\title{
Association of single nucleotide polymorphisms in miR- 499 and miR-196a with susceptibility to breast cancer
}

\author{
Abdolhassan Doulah $^{1 *}$, Ali Salehzadeh ${ }^{2}$, Majid Mojarrad ${ }^{3}$ \\ ${ }^{1}$ Department of Nursing, Faculty of Nursing and Midwifery, Ahvaz Branch, Islamic Azad University, Ahvaz, ${ }^{2}$ Department of \\ Biology, Rasht Branch, Islamic Azad University, Rasht, ${ }^{3}$ Department of Medical Genetics, School of Medicine, Mashhad \\ University of Medical Sciences, Mashhad, Iran
}

*For correspondence: Email: h_doulah@yahoo.com; Tel: +98-9163088656; Fax: +986133348351

Sent for review: 5 January 2016

Revised accepted: 2 January 2018

\begin{abstract}
Purpose: To investigate the relationship between miR-499 rs3746444 and miR-196a rs11614913 polymorphisms, and susceptibility to breast cancer in an Iranian population.

Methods: This case-control study was performed on a population of 200 subjects comprising 100 breast cancer patients (case/observation group) and 100 healthy individuals (control group). Amplification refractory mutation system-polymerase chain reaction (ARMS-PCR) was used to genotype these polymorphisms. $P$-values and odd ratios were determined, and $p$-values $<0.05$ and odd ratios $>1$ were considered statistically significant.

Results: There were no significant differences between observation and control groups with respect to rs11614913 T/C polymorphism. The rs11614913 $T$ allele was not identified as a risk factor for susceptibility to breast cancer $(O R=0.86,95 \% C l=0.85-1.3, p=0.46)$. However, there were significant differences between observation and control groups with respect to rs3746444 T/C polymorphism. It was observed that cytosine-cytosine $(C C)(O R=4.5,95 \% \mathrm{Cl}=1.3-15.4, p=0.06)$, and cytosine-thymine $(C T)(O R=1.9,95 \% \mathrm{Cl}=1-3.6, p=0.04)$ genotypes had protective influence against susceptibility to breast cancer.

Conclusion: These results indicate that CC and CT genotypes are associated with reduced risk of breast cancer. In particular, the presence of $C$ allele is significantly associated with a low risk of breast cancer. These findings may provide useful information for prevention and early diagnosis of breast cancer.
\end{abstract}

Keywords: Breast cancer, Early diagnosis, miR-196a rs11614913, miR-499 rs3746444, Polymorphism, ARMS-PCR

\begin{abstract}
This is an Open Access article that uses a funding model which does not charge readers or their institutions for access and distributed under the terms of the Creative Commons Attribution License (http://creativecommons.org/licenses/by/4.0) and the Budapest Open Access Initiative (http://www.budapestopenaccessinitiative.org/read), which permit unrestricted use, distribution, and reproduction in any medium, provided the original work is properly credited.
\end{abstract}

Tropical Journal of Pharmaceutical Research is indexed by Science Citation Index (SciSearch), Scopus, International Pharmaceutical Abstract, Chemical Abstracts, Embase, Index Copernicus, EBSCO, African Index Medicus, JournalSeek, Journal Citation Reports/Science Edition, Directory of Open Access Journals (DOAJ), African Journal Online, Bioline International, Open-J-Gate and Pharmacy Abstracts

\section{INTRODUCTION}

Breast cancer is the most common malignancy among women: about one million new patients are added annually to the world population of female breast cancer patients. This cancer accounts for $10 \%$ of all cancers and $23 \%$ of female cancers in developed countries [1].

There are more than 1000 microRNA (miRNA) genes in the human genome which regulate the translation or degradation of human messenger 
RNA (mRNA) by a complement sequence. Genetic variations in a miRNA may affect its maturation and biogenesis, and these are linked to the pathogenesis of a lot of diseases, which include breast cancer [2]. Researchers have shown that genetic polymorphisms are one of the main causes of individual differences in cancer prevalence. Single nucleotide polymorphisms (SNPs) in miRNAs can be used as genetic markers for prognosis breast cancer susceptibility or prediction [3].

Several miRNAs are abnormally expressed in breast cancer tissue when compared with normal breast tissue. These include miR-196a and miR499. Indeed, miR-196a is exceedingly expressed in breast cancer tissue [4]. Moreover, several studies have recognized genetic variants in the precursor miRNA sequence of miR-499 rs3746444 as possible biomarkers related to the etiology of breast cancer [5].

There are a few molecular and epidemiological studies on the association between breast cancer and polymorphisms in miR-499 rs3746444 and miR-196a rs11614913 [6].

To the best of our knowledge, there are no reports on the association between miR-196a rs11614913 and miR-499 rs3746444 polymorphisms, and the risk of breast cancer in an Iranian population.

In order to investigate if such association exist, a hospital-based case-control study on an Iranian population was carried out in this study, based on genotyping analysis applying amplification refractory mutation system-polymerase chain reaction (ARMS-PCR) assay.

\section{EXPERIMENTAL}

\section{Patients}

Whole blood samples were collected from healthy females and females with breast cancer in the teaching hospital of Mashhad University of Medical Sciences, Iran. A total of 100 control samples were chosen from different ages (18 61 ), while 100 breast cancer cases were selected from female patients aged $45-64$ years. Each patient included in the study gave informed consent. The study protocol conformed with the ethical codes of the 1975 Declaration of Helsinki [7], and was approved by the local Research and Medical Ethics Committee (approval ref. no. IR.IAU.5106930121003). All samples were collected in the hospital according to Iranian medical ethics.

\section{DNA isolation and amplification}

A 5-mL sample of peripheral whole blood was collected from each subject into an EDTA anticoagulant tube. Genomic DNA was extracted using High Pure PCR Template Preparation Kit (Roche Diagnostics, GmbH, Mannheim, Germany) according to the manufacturer's protocol. The miR-196a and miR-499 gene SNPs were analyzed using ARMS-PCR. In this method, three primers were used to amplify the rs11614913 and rs3746444 SNPs (Table I). The PCR reactions were prepared using Taq DNA Polymerase (Ampliqon, Denmark) according to the manufacturer's manual. The conditions of PCR were: initial denaturation at $95^{\circ} \mathrm{C}$ for $5 \mathrm{~min}$, 33 cycles of denaturation $\left(95{ }^{\circ} \mathrm{C}\right.$ for $\left.30 \mathrm{~s}\right)$, annealing $\left(60^{\circ} \mathrm{C}\right.$ for $\left.30 \mathrm{~s}\right)$, extension $\left(72^{\circ} \mathrm{C}\right.$ for $40 \mathrm{~s})$, and a final extension step $\left(72{ }^{\circ} \mathrm{C}\right.$ for 10 min). The PCR products were mixed by power load stain and ran in a $1 \%$ agarose gel.

Table 1: Primer sequences for the detection of mir$146 \mathrm{a}$ and miR-499 gene polymorphisms

\begin{tabular}{|c|c|c|}
\hline Gene & SNP & Primer Sequence $\left(5^{\prime} \rightarrow 3^{\prime}\right)$ \\
\hline $\begin{array}{l}\mathrm{miR}- \\
196 \mathrm{a}\end{array}$ & rs11614913 & $\begin{array}{l}\text { TCTCTAgTCCTTAgggAggT } \\
\text { ACCgACTgATgTAACTCTgg } \\
\text { ACCgACTgATgTAACTCTgA }\end{array}$ \\
\hline $\begin{array}{l}\mathrm{miR}- \\
499\end{array}$ & rs3746444 & $\begin{array}{l}\text { TCTATgAgAATTATgCgggC } \\
\text { AgCACAgACTTgCTgTCAC } \\
\text { AgCACAgACTTgCTgTCAT }\end{array}$ \\
\hline
\end{tabular}

\section{Statistical analysis}

To examine the differences in allele frequencies, chi-square $\left(x^{2}\right)$ analysis was used and the distribution of genotypes between case and control samples was calculated using (SPSS v. 22). The association between genotype and risk of breast cancer was evaluated by calculating the odds ratio (OR) and their $95 \%$ confidence intervals $(95 \% \mathrm{Cl})$ with logistic regression models. All statistical tests were two-sided. Values of $\mathrm{OR}>1$, and $p$ values $<0.05$ were considered statistically meaningful, indicating the effect of allele distribution on breast cancer probability.

\section{RESULTS}

The frequency distribution of miR-196a rs11614913 T/C genotypes in breast cancer patients and normal subjects is presented in Table 2. There were no significant differences in rs11614913 T/C polymorphism between the breast cancer patients and controls. Thus, miR196a rs11614913 T/C polymorphism was not identified as a risk/protection factor for susceptibility to breast cancer. In addition, the 
rs11614913 T allele was not identified as a risk factor for susceptibility to breast cancer $(\mathrm{OR}=$ $0.86,95 \% \mathrm{Cl}=0.85-1.3, p=0.46$ ).

The frequency distributions of miR-499 rs3746444 T/C genotypes in breast cancer patients and normal subjects are presented in Table 3. There were significant differences between the breast cancer group and the control group samples with respect to genotypes or alleles according to the $\left(x^{2}\right)$ analysis of data. The $\mathrm{CC}(\mathrm{OR}=4.5,95 \% \mathrm{Cl}=1.3-15.4, p=0.06)$ and CT $(\mathrm{OR}=1.9,95 \% \mathrm{Cl}=1-3.6, p=0.04)$ genotypes had protective effect on breast cancer. In addition, individuals with $\mathrm{C}$ allele presented a low risk for breast cancer development $(\mathrm{OR}=2.03,95 \% \mathrm{Cl}=1.3-3.3, p=$ 0.003).

Table 2: Genotype and allele frequencies of rs11614913 (C/T) polymorphism for breast cancer patients and healthy subjects

\begin{tabular}{|c|c|c|c|c|}
\hline Genotype & $\begin{array}{c}\text { Case } \\
(\%)\end{array}$ & $\begin{array}{c}\text { Control } \\
\text { (\%) }\end{array}$ & OR(95\%Cl) & $\begin{array}{c}P- \\
\text { value }\end{array}$ \\
\hline CC & $33(33.7)$ & $25(25)$ & 1 (reference) & \\
\hline CT & $51(52)$ & $62(62)$ & $\begin{array}{c}0.62(0.33- \\
1.18)\end{array}$ & 0.15 \\
\hline TT & $14(14.3)$ & $13(13)$ & $\begin{array}{c}0.82(0.33- \\
2)\end{array}$ & 0.66 \\
\hline \multicolumn{5}{|l|}{ Allele } \\
\hline $\begin{array}{l}C \\
T\end{array}$ & $\begin{array}{c}117(60) \\
79(40)\end{array}$ & $\begin{array}{c}112(56) \\
88(44)\end{array}$ & $\begin{array}{c}1 \text { (reference) } \\
0.86(0.58- \\
1.3)\end{array}$ & $-\overline{-}$ \\
\hline
\end{tabular}

Table 3: Genotype and allele frequencies of rs3746444 (T/C) polymorphism for breast cancer patients and healthy subjects

\begin{tabular}{lcccc}
\hline Genotype & $\begin{array}{c}\text { Case } \\
(\%)\end{array}$ & $\begin{array}{c}\text { Control } \\
(\%)\end{array}$ & OR(95\%Cl) & $\boldsymbol{P}$ \\
\hline TT & $35(43.8)$ & $63(63)$ & $\begin{array}{c}1 \\
\text { (reference) }\end{array}$ & - \\
CT & $35(43.8)$ & $33(33)$ & $\begin{array}{c}1.9(1-3.6) \\
4.5(1.3-\end{array}$ & 0.04 \\
CC & $10(12.5)$ & $4(4)$ & $15.4)$ & \\
& & & 1 & - \\
Allele & & & & \\
T & $105(66)$ & $159(79.5)$ & $\begin{array}{c}1 \\
\text { (reference) }\end{array}$ & 0.003 \\
C & $55(34)$ & $41(20.5)$ & $\begin{array}{c}2.03(1.3- \\
3.3)\end{array}$ & 0.003 \\
& & & & \\
\hline
\end{tabular}

\section{DISCUSSION}

The present research was conducted to assess the association between polymorphisms in miR499 rs3746444 and miR-196a rs11614913, and breast cancer development, in view of absence of such studies in an Iranian population [8]. Numerous associations between miRNAs and incidence of breast cancer have been demonstrated experimentally. An understanding of the mechanisms involved in these associations is crucial for the use of miRNAs markers as strong tools for the blockage and treatment of breast cancer [9].

The miRNAs are involved in several critical biological processes such as development, proliferation, differentiation and apoptosis. Genetic polymorphisms in miRNAs (SNPs) can potentially affect the selection or processing of miRNA targets. Several recent studies have assessed the association between SNPs in miR196a rs11614913 and miR-499 rs37464, and susceptibility to breast cancer $[5,10]$. In view of the important roles of miR-499 rs3746444 and miR-196a rs11614913 in the etiology of breast cancer, the present study evaluated the distribution of these genotypes and assessed the risk of breast cancer development in Iranian women.

The results obtained indicate that rs 11614913 polymorphism is not associated with an increased risk of breast cancer in this casecontrol study in Iranian women. This is in agreement with the results obtained by Jedlinski et al who reported that there was no relation between rs11614913 polymorphism and breast cancer in Caucasian case-control cohort in Queensland, Australia [11]. Similarly, a study conducted on a Brazilian female population found no relation between rs11614913 polymorphism and breast cancer [12]. In addition, Catucci et al reported that there was no statistical correlation between the existence of miR-196a rs11614913 in women affected by breast cancer and controls in German and Italian populations [8]. However, the results obtained in the present study are at variance with those reported by $\mathrm{Hu}$ et al and Hoffman et al who established an association between rs 11614913 and the risk of breast cancer. Some populationspecific factors, such as differences in genetic background, environmental factors, or lifestyle might explain these discrepancies in relation between rs11614913 polymorphism and breast cancer $[10,13]$.

Many case-control studies have explored the relation between SNP in miR-499 and risk of different kinds of cancer [14]. Polymorphism in miR-499 rs3746444 has been shown to be distinctly correlated with a variety of diseases, including breast cancer [10,15]. Yet, only a few epidemiological studies have focused on the association between miR-499 rs3746444 polymorphisms and risk of breast cancer.

In the present study, the association between miR-499 rs3746444 polymorphism and breast cancer risk was investigated. The results indicate 
an association between rs3746444 polymorphism and breast cancer susceptibility. In addition, CC and CT genotypes were associated with a protective effect against breast cancer. Furthermore, women with $\mathrm{C}$ allele had a low risk for breast cancer development. Consistent with these findings, a significant association has been demonstrated between rs3746444 polymorphism and breast cancer risk in an Asian population [5]. Moreover, $\mathrm{Xu}$ et al reported breast cancer risk among a Chinese population with respect to rs3746444 polymorphism [16]. A recent research by Sun et al also showed a statistically significant association between miRNA-499 rs3746444 polymorphism and cancer susceptibility in Asians, but not in Caucasian population [17].

Although the results of this study did not suggest any association between rs11614913 in miR$196 \mathrm{a}$ and risk of breast cancer, there are some evidence that miR-196a may play a major role in carcinogenesis. Among the possible targets of miR-196a are genes that take part in various cancer-related pathways. The split of HOX gene products similar to HOXB8 mRNA has been shown to be relatively due to miR-196a.

The HOX genes regulate a number of genes that, in turn, regulate huge networks of alternative genes. Thus, they are involved in some key biological processes. Furthermore, the potential targets of miR-196a are LSP1 and TOX3, which are new breast cancer susceptibility genes recently identified in a whole-genome association research. It is probable that the rs11614913 SNP modulates the acts of these two genes in breast cancer progress. However, this is yet to be established [18].

\section{Limitations of the study}

It was not possible to investigate preciselyestablished risk factors (age at menopause, age at menarche, hormone replacement therapy, and family history) to detect gene-environment interaction effects.

\section{CONCLUSION}

The findings of this study indicate that SNP in miR-499 rs3746444 plays a pivotal role in the development of breast cancer in the Iranian population investigated. However, there is no significant association between miR-196a rs11614913 SNP and breast cancer susceptibility. However, well-designed studies involving larger population samples are required to establish more firmly the associations of these miRNA SNPs with risk of breast cancer.

\section{DECLARATIONS}

\section{Acknowledgement}

The authors acknowledge Islamic Azad University, Ahvaz Branch (Iran) for the financial support for this research.

\section{Conflict of interest}

The authors declare that no conflict of interest is associated with this work.

\section{Contribution of authors}

We declare that this work was done by the authors named in this article and all liabilities pertaining to claims relating to the content of this article will be borne by the authors. Mojarrad M. and Salehzadeh A. studied the concepts and collected the samples. Doulahand Mojarrad M. collected the data and did laboratory tests. Salehzadeh A. analyzed the data and drafted the article.

\section{REFERENCES}

1. Coley H. Mechanisms and strategies to overcome chemotherapy resistance in metastatic breast cancer. Cancer Treat Rev 2008; 34: 378-390.

2. Ryan $B$, Robles $A$, Harris $C$. Genetic variation in microRNA networks: the implications for cancer research. Nat Rev Cancer 2010; 10: 389-402.

3. Pooly K, Healey $C$, Smith $P$, Pharoah $P$, Thompson D, Tee L, West J, Jordan C, Easton D, Ponder B, et al. Association of the Progesterone Receptor Gene with Breast Cancer Risk: A Single-Nucleotide Polymorphism Tagging Approach. Cancer Epidemiol Biomarkers Prev 2006; 15(4): 675-682.

4. Iorio $M$, Ferracin $M$, Liu C, Veronese $A$, Spizzo $R$, Sabbioni S, Magri E, Pedriali M, Fabbri M, Campiglio M, et al. MicroRNA gene expression deregulation in human breast cancer. Cancer Research 2005; 65: 7065-7070.

5. Chen $P$, Zhang J, Zhou F. miR-499 rs3746444 polymorphism is associated with cancer development among Asians and related to breast cancer susceptibility. Mol Biol Rep 2012; 39: 10433-10438.

6. Zhou B, Wang $K$, Wang $Y$. Common genetic polymorphisms in pre-microRNAs and risk of cervical squamous cell carcinoma. Mol Carcinog 2011; 50: 499505.

7. World Medical Association Declaration of Helsinki: ethical principles for medical research involving human subjects. JAMA 2013; 310(20):2191-2194.

8. Catucci I, Verderio $P$, Pizzamiglio $S$, Manoukian $S$, Peissel B, Zaffaroni D, Roversi G, Ripamonti C, Pasini $B$, Barile $M$, et al. The CASP8 rs3834129 polymorphism 
and breast cancer risk in BRCA1 mutation carriers. Breast Cancer Res Treat 2011; 125(3): 855-860.

9. McCafferty $M$, McNeill R, Miller N, Kerin M. Interactions between the estrogen receptor, its cofactors and microRNAs in breast cancer. Breast Cancer Res Treat 2009; 116: 425-432.

10. Hoffman A, Zheng T, Yi C, Leaderer D, Weidhaas J, Slack F, Zhang Y, Paranjape T, Zhu Y. MicroRNA miR 196a-2 and breast cancer: a genetic and epigenetic association study and functional analysis. Cancer Research 2009; 69: 5970-5977.

11. Jedlinski D, Gabrovska N, Weinstein S, Smith R, Griffiths L. Single Nucleotide Polymorphism in mir-196a and Breast Cancer Risk: A Case Control Study. Twin Research and Human Genetics 2011; 14(5): 417-421.

12. Linhares J, Azevedo M, Siufi A, Valleta C, Wolgien G, Noronha $E$, Bonetti $T$, da Silva $D$. Evaluation of single nucleotide polymorphisms in microRNAs (miR-196a rs11614913 C/T) from Brazilian women with breast cancer. BMC Medical Genetics 2012; 13: 119-124.

13. Hu Z, Liang L, Wang Z, Tian T, Zhou X, Chen J, Miao R, Wang $Y$, Wang $X$, Shen $H$. Common genetic variants in
pre-microRNAs were associated with increased risk of breast cancer in Chinese women. Hum Mutat 2009; 30: 79-84.

14. Xiang Y, Fan S, Cao J, Huang S, Zhang L. Association of the microRNA-499 variants with susceptibility to hepatocellular carcinoma in a Chinese population. Mol Biol Rep 2012; 39: 7019-7023.

15. Min K, Kim J, Jeon Y, Jang M, Chong S. Association of the miR-146aC.G, 149C.T, 196a2C.T, and 499A.G polymorphisms with colorectal cancer in the Korean population. Mol Carcinog 2012; 51(1): 65-73.

16. $X u Y$, GU L, Pan Y, Li R, Gao T, Song G, Nie Z, Chen L, Wang $S$, He B. Different effects of three polymorphisms in MicroRNAs on cancer risk in Asian population: evidence from published literatures. PLoS One 2013; 8(6): e65123.

17. Sun $H$, Li Q, Yang T, Wang W. Quantitative assessment of the association between microRNA-499 rs3746444 A/G polymorphism and cancer risk. Tumour Biol. 2014; 35: 2351-1238.

18. Yekta S, Shih I, Bartel D. MicroRNA directed cleavage of HOXB8 mRNA. Science 2004; 304(5670): 594-596. 